Document downloaded from:

http://hdl.handle.net/10251/134138

This paper must be cited as:

Chieregato, A.; Soriano Rodríguez, MD.; Basile, F.; Liosi, G.; Zamora Blanco, S.; Concepción Heydorn, P.; Cavani, F.... (2014). One-pot glycerol oxydehydration on multifunctional catalysts: influence of acid and redox properties on the catalytic performance. Applied Catalysis B Environmental. 150-151:37-46.

https://doi.org/10.1016/j.apcatb.2013.11.045

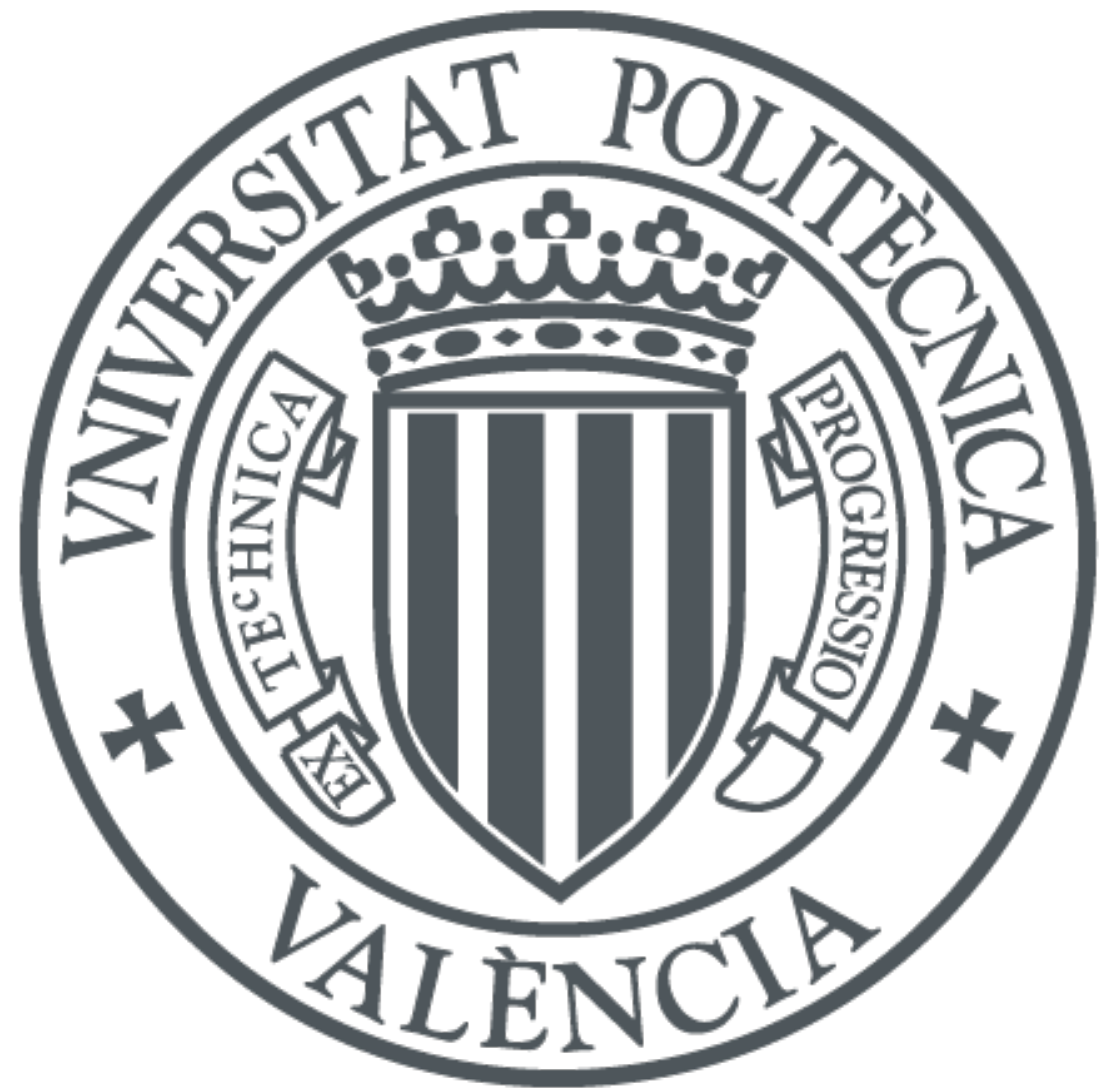

The final publication is available at

https://doi.org/10.1016/j.apcatb.2013.11.045

Copyright Elsevier

Additional Information 


\title{
One-pot glycerol oxidehydration to acrylic acid on multifunctional catalysts: Focus on the influence of the reaction parameters in respect to the catalytic performance
}

\author{
Alessandro Chieregato ${ }^{1}$, M. Dolores Soriano ${ }^{2}$, Francesco Basile ${ }^{1}$, Giuseppe Liosi ${ }^{1}$, Segundo Zamora ${ }^{2}$, \\ Patricia Concepción², Fabrizio Cavani*, José M. Lopez Nieto*
}

1. Dipartimento di Chimica Industriale e dei Materiali, ALMA MATER STUDIORUM Università di Bologna, Viale Risorgimento 4, 40136 Bologna, Italy. Also: INSTM, Research Unit of Bologna.

2. Instituto de Tecnología Química, UPV-CSIC, Campus de la Universidad Politécnica de Valencia, Avda. Los Naranjos s/n; 46022 Valencia (Spain)

\begin{abstract}
We report here about an investigation of the key catalyst features and reaction parameters in glycerol oxidehydration into acrylic acid over $\mathrm{W}-\mathrm{V}-\mathrm{Nb}$ mixed oxides with the hexagonal tungsten bronze structure. The incorporation of $\mathrm{Nb}$ allowed to considerably improve the catalytic behaviour not only because of the higher yield to acrylic acid and acrolein compared to $\mathrm{W}-\mathrm{V}$ bronzes, but also to increase of more than order of magnitude the oxygenated productivity rate, because of the greater concentration of glycerol used in the inlet feed and the lower contact time needed. Experiments were carried out by reacting acrolein, and by oxidation of methanol, as a model molecule for the determination of surface acid and redox properties. These experiments demonstrated that with the $\mathrm{W}-\mathrm{V}-\mathrm{Nb}$ catalyst the optimal ratio between the two consecutive steps of acid-catalysed glycerol dehydration and acrolein oxidation, and between the two parallel reactions of acrolein oxidation and transformation into by-products (ketals and oligomers), was achieved in the presence of defined glycerol-to-oxygen inlet ratio. Indeed, oxygen played the fundamental role of accelerating the oxidation of the intermediately formed acrolein into acrylic acid, by allowing a greater concentration of the oxidizing $\mathrm{V}^{5+}$ sites.
\end{abstract}




\section{Introduction}

With the aim of reducing the carbon footprint of fuels, bio-diesel represents one of the most important options, theoretically providing neutral $\mathrm{CO}_{2}$ balance and significant reduction of greenhouse gas emission. ${ }^{1-3}$ The increasing trend of biodiesel production goes hand-in-hand with the availability of large volumes of glycerol that is co-produced in the conventional transesterification reaction exploited to synthesize the bio-fuel. ${ }^{2,4}$ Since the late 90 s, this abundance of glycerol has significantly impacted the glycerin market resulting in a decline of its price, ${ }^{5,6}$ and finally making glycerol a low-cost raw material desirable to be converted into different chemicals with higher economic value. On the other hand, it must be mentioned that starting from 1997 the glycerin market has faced very volatile conditions, increasing price and actual shortage of refined glycerol supply, ${ }^{7}$ that nowadays renders difficult any accurate economic evaluation of chemical processes designed for its transformation. However, since the over-supply of crude glycerol from biodiesel production (Bio-Crude) is actually one of the main reasons for price volatility, the transformation of glycerol toward more added-value products represents a key-point so as to develop a new bio-based chemical industry.

Amongst the several options focused on glycerol conversion, a great deal of attention has been paid to the dehydration of glycerol into acrolein, ${ }^{1,4,7-31}$ and more recently also to the oxidehydration of glycerol into acrylic acid. ${ }^{32-42}$ From an economic and an engineering point of view, an interesting option to perform the latter reaction is the one-pot (single-step) transformation, by means of a multifunctional catalyst able to carry out both the dehydration of glycerol into acrolein and aldehyde oxidation into acrylic acid. Indeed, the use of a single catalyst can simplify the reactor engineering and level the heat balance between the endothermic dehydration of glycerol and the exothermic oxidation step. 
Previously we reported that W-V oxides with hexagonal tungsten bronze (HTB) structure and $\mathrm{V}^{4+}$ incorporated in $\mathrm{WO}_{3}$ lattice are effective catalysts for the direct synthesis of acrylic acid from glycerol; ${ }^{38}$ under the best conditions these systems showed $25 \%$ acrylic acid yield plus $11 \%$ yield to residual acrolein. Later, we studied the influence of $\mathrm{Nb}$ addition to V-doped HTB structures, with the aim of improving the acidic features of the catalysts so as to enhance the glycerol dehydration step. Three-component catalysts (W-V-Nb) further increased the catalytic performance, finally leading to $33 \%$ acrylic acid yield plus $17 \%$ yield to residual acrolein; ${ }^{41}$ moreover, since the optimum working condition for $\mathrm{W}-\mathrm{V}-\mathrm{Nb}$ catalysts is located at a much lower contact time (from $0.38 \mathrm{~s}$ to 0.15 s) than for the W-V system, the catalyst productivity was also consistently increased.

In order to fully investigate the catalyst activity of the best performing tri-component sample (reported as WVNb-1 sample) ${ }^{41}$, we report here a complete study of the catalyst behavior as a function of the inlet feed composition. Moreover, it is here reported about the methanol gas-phase transformation into formaldehyde and dimethyl ether (DME) on both $\mathrm{W}-\mathrm{V}$ and $\mathrm{W}-\mathrm{V}-\mathrm{Nb}$ catalysts; indeed, methanol is known to be a suitable probe to explore the acid and redox properties of metal oxides. ${ }^{45,46}$ The results obtained allow to draw important and general conclusions on the catalyst features needed to convert oxygenated molecules by means of direct processes, using a single multifunctional catalyst.

Finally, so as to support the conclusions depicted on HTB doped structures, the same reactions were carried out on Mo-V-(W) oxides with laminar structure. In order to obtain a complete picture of the catalysts behavior, the acrolein oxidation reaction was also studied on both HTBs and laminar-type oxides.

\section{Experimental}

\subsection{Synthesis of $W-V, W-V-N b$ HTBs and Mo-V-(W) laminar oxide}


W-V and W-V-Nb catalysts were prepared hydrothermally from gels obtained from aqueous solution of the corresponding salts. The hydrothermal synthesis was carried out at $175^{\circ} \mathrm{C} 48 \mathrm{~h}$. Then the solid were washed, dried at $100^{\circ} \mathrm{C}$ overnight. Finally the solids were heat-treated in $\mathrm{N} 2$ at $600^{\circ} \mathrm{C}$ during $2 \mathrm{~h}$. More details on the preparation have already been reported elsewhere. ${ }^{38,41}$

Mo-V-(W) catalyst was prepared by evaporation method; an aqueous solution of ammonium heptamolybdate, vanadyl sulphate and ammonium tungstate was evaporated in rotavapor. The solid was dried at $100^{\circ} \mathrm{C}$ overnight and then calcined in air at $350^{\circ} \mathrm{C}$. Finally the solid was heattreated in $\mathrm{N}_{2}$ at $500^{\circ} \mathrm{C}$ for $2 \mathrm{~h}$. (Josè: MORE DETAILS ON THE LATTER CATALYST ?).

\subsection{Catalysts characterization}

Surface areas were obtained from $\mathrm{N}_{2}$ adsorption isotherms using the BET method; a Micromeritics ASAP 2000 instrument was used. The samples were degassed in-situ under vacuum at a temperature of $250^{\circ} \mathrm{C}$. Metal atomic composition of both hydrothermal and heated samples was determined by inductive coupled plasma (ICP). Powder X-ray diffraction patterns (XRD) were collected using a PANalytical X'Pert PRO diffractometer with CuK $\alpha$ radiation and an X'Celerator detector in Bragg-Brentano geometry. Unit cell parameters were refined using the program FullProf. ${ }^{25}$ Termogravimetric analysis (TG) was performed on a Mettler Toledo (TGA/SDTA 851) instrument in the temperature range $20-700^{\circ} \mathrm{C}$ with a $0.02 \mathrm{~g}$ sample. The heating rate was $10^{\circ} \mathrm{C} \mathrm{min}-$ ${ }^{1}$ and the flow air $100 \mathrm{ml} \mathrm{min}^{-1}$.

Infrared spectra were recorded at room temperature in the $300-4000 \mathrm{~cm}^{-1}$ region with a Nicolet 205xB spectrophotometer equipped with a Data station at a spectral resolution of $1 \mathrm{~cm}^{-1}$ and accumulations of 128 scans. Raman spectra were obtained with an "in via" Renishaw spectrometer, equipped with an Olympus microscope. The exciting wavelength was $785 \mathrm{~nm}$ from a Renishaw HPNIR laser with a power of approximately $15 \mathrm{~mW}$ on the sample. Dehydration of 
catalysts was carried out using a home-designed microreactor for in situ Raman spectroscopy measurement. The samples were dehydrated under $20 \mathrm{ml} \mathrm{min} \mathrm{m}^{-1}$ argon flow at $150^{\circ} \mathrm{C}$.

Temperature-programmed reduction (TPR) experiments were carried out on 10-20 mg of catalyst with a $\mathrm{N}_{2}: \mathrm{H}_{2}$ flow $\left(10 \% \mathrm{H}_{2}\right.$, total flow $\left.50 \mathrm{ml} \mathrm{min}{ }^{-1}\right)$. The temperature range explored was from room temperature to $650^{\circ} \mathrm{C}$. The heating rate was maintained at $10^{\circ} \mathrm{C} \mathrm{min}^{-1}$. Temperatureprogrammed desorption of ammonia (TPD) experiments were carried out on a TPD/2900 apparatus from Micromeritics. $0.30 \mathrm{~g}$ of sample was pre-treated in a He stream at $450^{\circ} \mathrm{C}$ for $1 \mathrm{~h}$. Ammonia was chemisorbed by pulses at $100^{\circ} \mathrm{C}$ until equilibrium was reached. Then, the sample was fluxed with He stream for $15 \mathrm{~min}$, prior to increasing the temperature up to $500^{\circ} \mathrm{C}$ in a helium stream of $100 \mathrm{ml}$ $\min ^{-1}$ and using a heating rate of $10^{\circ} \mathrm{C} \mathrm{min}-1$. The $\mathrm{NH}_{3}$ desorption was monitored with a thermal conductivity detector (TCD) and a mass-spectrometer following the characteristic mass of ammonia at 15 a.m.u.

X-ray photoelectron spectroscopy (XPS) measurements were performed on a SPECS spectrometer equipped with a Phoibos 150 MCD-9 detector using a monochromatic Al K-alpha (1486.6 eV) X-ray source. Spectra were recorded using analyzer pass energy of $50 \mathrm{~V}$, an X-ray power of $200 \mathrm{~W}$, and an operating pressure of 10-9 mbar. Spectra treatment was performed using the CASA software. Binding energies (BE) were referenced to $\mathrm{C} 1 \mathrm{~s}$ at $284.5 \mathrm{eV}$.

\subsection{Reactivity experiments}

Reactivity experiments for glycerol, acrolein and methanol transformation were carried out using a continuous flow reactor made of glass, operating at atmospheric pressure. An amount of catalyst ranging from 0.1 to $0.3 \mathrm{~g}$ of catalyst was loaded in the form of powder. Overall reactor gas residence time was varied. Inlet feed molar ratios were also varied according to the desired compositions. For each condition, all the reaction parameters are always specified in each figure. 
For both glycerol oxidehydration and acrolein oxidation the effluent stream was bubbled through two in-series abatement devices, which were filled with water (but in some cases anhydrous acetone was used, for the identification of compounds which are less soluble in water) and maintained at a temperature of $0-2^{\circ} \mathrm{C}$; a third refrigerated condenser was left unfilled with any solvent. After this abatement, the gaseous stream, still containing oxygen and carbon oxides, was fed to an automatic sampling system for gas-chromatography (GC-TCD) analysis. The water solution containing the unconverted glycerol and reaction products was analyzed by GC, using a HewlettPackard 5890 instrument equipped with a FID detector. A semi-capillary wide-bore OV 351 (polyethylenglycol treated with terephthalic acid) column was used for the separation of condensed compounds; oven temperature was set from $40^{\circ} \mathrm{C}$ to $190^{\circ} \mathrm{C}$ (heating rate $10^{\circ} / \mathrm{min}$, isothermal step at $190^{\circ} \mathrm{C}, 3 \mathrm{~min}$ ), then from $190^{\circ} \mathrm{C}$ to $225^{\circ} \mathrm{C}$ (heating rate $30^{\circ} / \mathrm{min}$, final isothermal step at $225^{\circ} \mathrm{C}, 30$ min). Two wide-bore columns were used for the separation of uncondensable products: a Molsieve $5 \mathrm{~A}$ for oxygen and $\mathrm{CO}$, and a Silica Plot for $\mathrm{CO}_{2}$ (oven temperature $80^{\circ} \mathrm{C}$ ). Compounds were identified by means of both GC-MS and the injection of pure reference standards for the comparison of retention times in the GC column. A few unknown compounds were eluted in the GC column; we attributed to these compounds the same response factor of the corresponding known compound with the closest retention time. In the figures included with this paper, minor identified products and unknown compounds have been grouped together under the heading "Others".

Josè: SPECIFIC REACTION PARAMETERS FOR METHANOL REACTION

\section{Result and discussion}

\subsection{Characterization of mixed-oxide catalysts}

Josè: you should write this part. The figures and Tables, those which you sent us, are at the end of the paper. 


\subsection{Reactivity experiments: oxidehydration of glycerol on W-V-Nb with HTB structure}

In order to examine the catalyst activity of W-V-Nb sample (WVNb-1 in ref [41]), the inlet feed composition was varied; for each value of oxygen-to-glycerol ratio, the catalytic performance was analyzed in the temperature range $260-410^{\circ} \mathrm{C}$. Specifically, Figure $\mathrm{N}+1$ reports the catalytic results obtained at $265^{\circ} \mathrm{C}$, where the maximum acrylic acid yield was registered (however, analogous trends were obtained for the other temperatures examined). In this experiment both the glycerol molar content in feed (6\%) and the water one (40\%) were kept constant; oxygen molar and inert gas $(\mathrm{He})$ molar contents were varied so as to satisfy both the desired feed composition and the pursued residence time. The latter was always set constant to $0.15 \mathrm{~s}$ (measured at room temperature).

When a stoichiometric amount of oxygen and glycerol was fed (ratio 3:6), the glycerol conversion was close to $50 \%$ and very low selectivity to both acrolein and acrylic acid were registered. On the other hand, selectivity into heavy compounds was very high. Increasing the amount of oxygen, the heavy compounds selectivity dropped in favor of selectivity to the other products; the acrylic acid selectivity trend showed a maximum (39\%) with the oxygen-to-glycerol molar ratio $12: 6$, finally decreasing in favor of carbon oxides.

Figure $\mathrm{N}+2$ shows the results of a set of experiments where the oxygen to glycerol molar ratio was kept constant equal to 2 , which showed to be the best ratio in Figure $\mathrm{N}+1$, but the inlet molar fraction of reactants was proportionally decreased compared to the ratio oxygen-to-glycerol 12:6. In spite of the constant optimal ratio between the reactants, the heavy compounds selectivity increased mainly in favor of acrylic acid when the molar fraction of reactants was decreased, which is the opposite one might expect based on the fact that higher reactants loading should favour condensation reaction leading to heavy compounds. This indicates that the most important 
parameter affecting catalytic behavior is the oxygen partial pressure; higher oxygen contents enhance the oxidation of the intermediately formed acrolein into acrylic acid, so limiting the undesired formation of acrolein condensation into by-products. When instead lower oxygen molar fractions are used, irrespectively of glycerol partial pressure (i.e., at both low and high glycerol partial pressure), the kinetically preferred reaction involves the transformation of acrolein into byproducts (Scheme 1). This strongly support the hypothesis that the rate-determining step in the redox mechanism of acrolein transformation into acrylic acid is the oxidation of the reduced $\mathrm{V}$ sites into $\mathrm{V}^{5+}$, the latter being the species involved in the aldehyde oxidation, and that the surface concentration of the oxidizing species is thus affected by oxygen partial pressure.

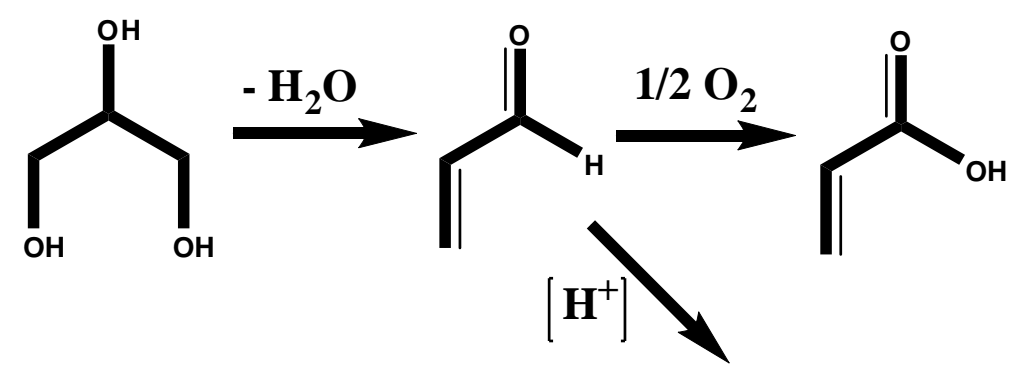

\section{Oligomers}

Scheme 1. The overall reaction mechanism for glycerol oxidehydration.

On the other hand, if the partial pressure of oxygen is too high, the selectivity to acrylic acid drops, with a concomitant increase of carbon oxides (Figure $\mathrm{N}+1$ ). These findings allow to draw the important conclusion that in order to minimize the undesired competitive reaction of heavier compounds formation, likely catalyzed by the same acid sites which are also required for the glycerol dehydration step, the crucial point is to develop a steady-state showing a controlled amount of oxidizing surface sites on catalyst surface.

Figure $\mathrm{N}+3$ compares the productivity into acrolein + acrylic acid for the $\mathrm{W}-\mathrm{V}$ catalyst ${ }^{41}$ and for the W-V-Nb catalyst under non optimized reaction conditions, ${ }^{38}$ with productivity achieved 
under the conditions shown in the present work, and with results reported in the literature as well. It is shown that the productivity achieved with $\mathrm{W}-\mathrm{V}-\mathrm{Nb}$ is by far higher than that previously reported, and also much better than that reported for other catalytic systems and for the two-catalyst inseries reactor configuration, which the alternative approach proposed in the literature. Indeed, the best value achieved of ca $2 \mathrm{~h}^{-1}$ is quite of significance for industrial processes aimed at the synthesis of bulk chemicals or intermediates.

\subsection{Reactivity experiments: oxidehydration of glycerol on W-V-Nb catalyst, time-on-stream test}

Figure $\mathrm{N}+4$ (top) shows the catalytic behavior of the $\mathrm{W}-\mathrm{V}-\mathrm{Nb}$ catalyst plotted in function of time-on-stream (tos), using the experimental conditions that allowed to obtain the best acrylic acid yield (feed molar ratio $\mathrm{O}_{2} / \mathrm{Gly} / \mathrm{H}_{2} \mathrm{O} / \mathrm{He}=12 / 6 / 40 / 40$, temperature $265^{\circ} \mathrm{C}$, residence time $0.15 \mathrm{~s}$ ). The yields shown in figs. $\mathrm{N}+1$ and $\mathrm{N}+2$ were obtained after ca 90 min tos, and well fit the trends here shown; on the other hand, after $6 \mathrm{~h}$ tos an activation phenomenon was registered. Indeed, until ca $40 \mathrm{~h}$ tos the consecutive selective oxidation of acrolein to acrylic acid was clearly favored, since the acrolein yield decreased in favor of acrylic acid. At ca $40 \mathrm{~h}$ tos, the highest $50 \%$ acrylic acid yield was registered. However, afterwards the catalyst started to deactivate and the selectivity to acrolein and acrylic acid inverted their trends. Figure $\mathrm{N}+4$ (bottom), plotting the yield to both acrolein and acrylic acid registered during experiments shown in Figure $\mathrm{N}+4$ (top), demonstrates that a clear kinetic relationship between acrolein and acrylic acid exists; indeed, the sum of yields to both compounds was always close to $55 \%$, even if the relative quantity of the two was consistently different during the period of the experiment.

The XRD analysis on the spent $\mathrm{W}$-V-Nb sample indicates that at the end of the lifetime experiment the catalyst structure was deeply changed with a loss of the HTB structure...... (Josè: 
ANY SUGGESTION AND COMMENT IS HERE VERY WELCOMED! ANY COMMENT FROM XPS/RAMAN ANALYSIS ON SPENT SAMPLE?).

More complex is the explanation for catalyst activation shown during the 6-to- $20 \mathrm{~h}$ tos; this might be due to the formation of different crystalline or amorphous surface structures. Indeed, the formation of more active amorphous structures is well known to occur on Mo-V-(W) catalysts, typically used to selectively oxidize acrolein into acrylic acid $^{44}$ and we cannot exclude that a similar phenomenon may occur on our W-V-Nb systems. Josè: here it should be necessary to characterise the catalyst downloaded after the first $20 \mathrm{~h}$ tos, that is after the activation has occurred; would it be possible to make TEM analysis of the freshly calcined, of the activated (after $20 \mathrm{~h}$ tos) catalyst and finally of deactivated catalysts ? We shall prepare samples and mail you.

\subsection{Reactivity experiments: reaction with methanol on $\mathrm{W}-\mathrm{V}$ and $\mathrm{W}-\mathrm{V}-\mathrm{Nb}$ catalysts}

Figures $\mathrm{N}+5$ and $\mathrm{N}+6$ report the results obtained when methanol was made react in the presence of oxygen on $\mathrm{W}-\mathrm{V}-\mathrm{Nb}$ and $\mathrm{W}-\mathrm{V}$ catalysts; this latter sample was investigated in detail for glycerol oxidehydration in a previous work. ${ }^{38}$ As a general trend, at low temperature the formation of dimethyl ether (DME) was favored over its oxidation into formaldehyde ( $\mathrm{HCHO}$ ) (higher ratio $\mathrm{DME} / \mathrm{HCHO}$ ); when the temperature was increased the DME-to-formaldehyde ratio decreased. At high temperature the decomposition and total oxidation were also favored, thus increasing the overall carbon oxides selectivity, mainly carbon monoxide through formaldehyde decomposition. Minor amounts of dimethoxymethane and methylformiate also formed.

Comparing the catalytic behavior of $\mathrm{W}-\mathrm{V}$ and $\mathrm{W}-\mathrm{V}-\mathrm{Nb}$, it is possible to notice that for the latter sample a much higher selectivity to DME was shown, in accordance with the higher acid strength of this sample. Increasing the temperature, the reaction of methanol oxidehydrogenation to formaldehyde kinetically prevailed over the etherification reaction; finally, at high methanol 
conversion (90\%) formaldehyde selectivity was almost identical for the two catalysts. Moreover, it is interesting to notice the different temperatures needed to reach similar conversions; for the W$\mathrm{V}-\mathrm{Nb}$ catalyst, $90 \%$ methanol conversion was shown at $330-335^{\circ} \mathrm{C}$, whereas for the $\mathrm{W}-\mathrm{V}$ catalyst the same conversion was achieved at $380^{\circ} \mathrm{C}$; this difference is attributable to higher surface specific surface area of the $\mathrm{Nb}$-containing sample, which is one of the main features of this catalyst compared to the $\mathrm{W}-\mathrm{V}$; moreover, a contribution to the higher activity may also derive from the faster reaction of methanol etherification. The $\mathrm{CO}$ selectivity also was slightly different for the two catalysts, respectively $10 \%$ for $\mathrm{W}-\mathrm{V}-\mathrm{Nb}$ and $16 \%$ for $\mathrm{W}-\mathrm{V}$ (at the same methanol conversion of $90 \%$ ).

\subsection{Reactivity experiments: acrolein conversion on $\mathrm{W}-\mathrm{V}$ and $\mathrm{W}-\mathrm{V}-\mathrm{Nb}$ catalysts}

Figure $\mathrm{N}+7$ compares the catalytic results obtained when acrolein was made react on $\mathrm{W}-\mathrm{V}$ and $\mathrm{W}-\mathrm{V}-\mathrm{Nb}$ catalysts. Under the same working conditions, the two catalyst showed important differences: W-V sample exhibited both lower acrolein conversion than $\mathrm{W}-\mathrm{V}-\mathrm{Nb}$, which again can be explained by taking into account the higher specific surface area of this latter sample, and lower selectivity into acrylic acid, with higher selectivity to heavy compounds. Therefore, It may be hypothesized that the improved acid features of this latter sample may help the desorption of acrylic acid, ${ }^{43}$ so limiting its combustion. On the other hand, the low selectivity to acrolein oligomers suggests that the aldehyde oxidation into acrylic acid is much faster than the side acid-catalysed reactions, which may also relate to the high concentration of $\mathrm{V}$ sites. The latter in turn is greatly affected by oxygen partial pressure (vide supra), but a role of $\mathrm{Nb}$ ions in facilitating the reoxidation of reduced $V$ sites cannot be excluded.

\subsection{Reactivity experiments: comparison with Mo-V-(W) laminar oxide}


With the aim of demonstrating the general conclusions drawn on W-V-Nb catalysts, showing superior performance compared to $\mathrm{W}-\mathrm{V}$, we report here the catalytic results obtained on Mo-V-(W) laminar oxide, which is a catalyst for the selective oxidation of acrolein into acrylic acid [REF].

Figure $\mathrm{N}+8$ reports the results obtained in the oxidehydration of glycerol using the same conditions found as optimal for $\mathrm{W}-\mathrm{V}-\mathrm{Nb}$. As highlighted by the catalyst characterization $\left(\mathrm{NH}_{3}\right.$ adsorption and $\mathrm{NH}_{3}$-TPD tests, fig. $\mathrm{N}$ ) this mixed oxide shows very poor acid properties; this finding is very well reflected on the reactivity results of both glycerol (fig. $\mathrm{N}+8$ ) and methanol (fig. $\mathrm{N}+9$ ). Indeed, when glycerol was made react on this catalyst very high selectivity to heavier compounds was registered since the unconverted glycerol can react with the produced aldehyde so as to form ketals (cyclic ethers). In fact, if the catalyst does not hold the acid properties needed to quickly and selectively dehydrate glycerol into acrolein, the formation of other by-products is detected, eg, cyclic ethers such as 1,3-dioxan-5-ol and 1,3-dioxolan-4-yl-methanol, formed by reaction between glycerol and formaldehyde or acetaldehyde, the latter compounds being in turn formed by retroaldol condensation of 3-hydroxy-propanal, one product of glycerol mono-dehydration. ${ }^{35}$ The intermediately formed acrolein can react in a similar way with glycerol to form other cyclic ethers as reported in Scheme 2; indeed, the formation of these ethers was confirmed by means of ESI-MS analysis of the reaction mixture. 


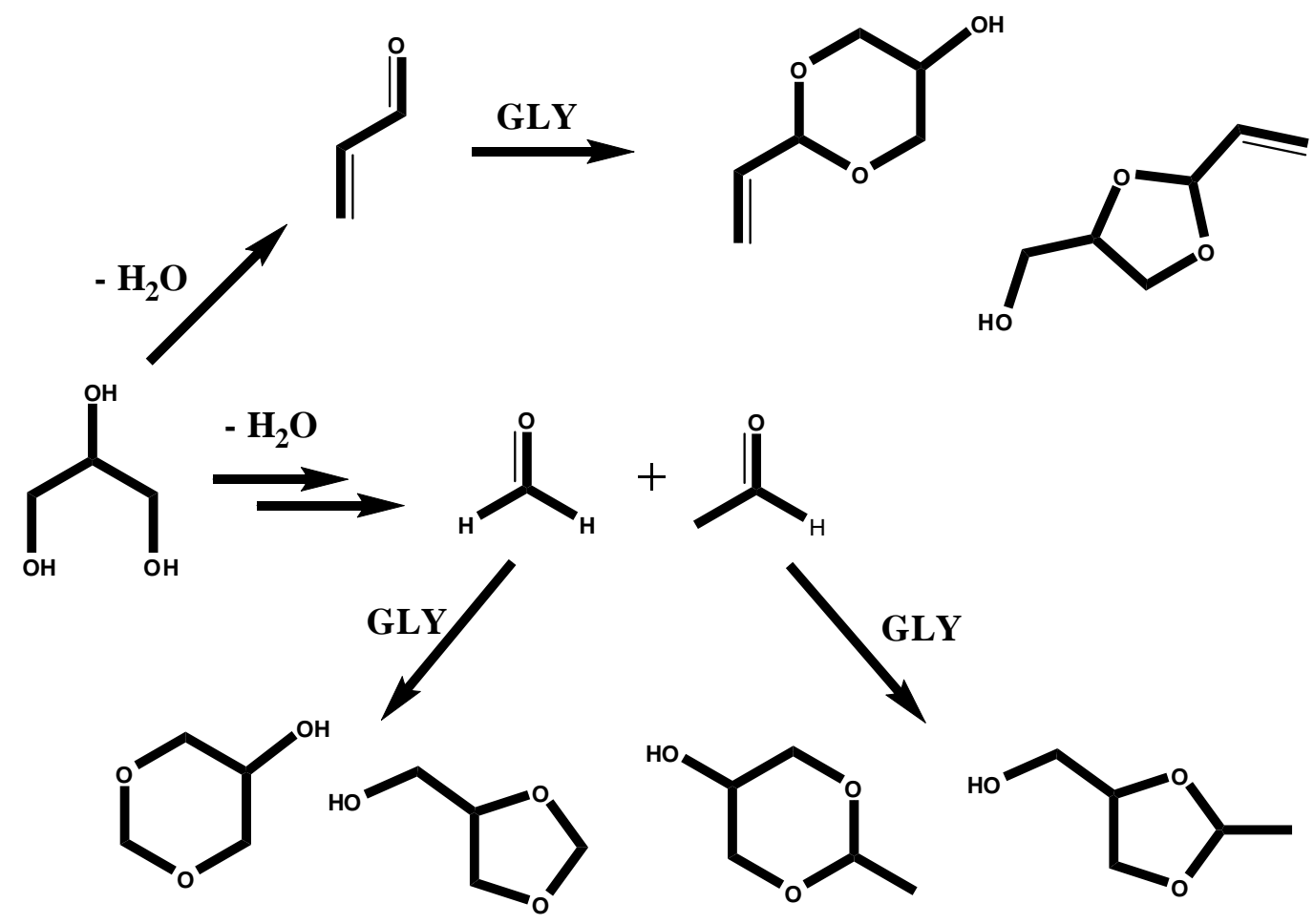

Scheme 2. Ketals formation pathways as by-products of the glycerol oxidehydration reaction.

When the temperature was raised the ketals selectivity decreased mainly in favor of COx and acrolein formation; on the other hand, the acrylic acid selectivity remained limited, even if the catalyst is specifically designed for acrolein oxidation into acrylic acid. Apparently, this was due to both the low selectivity to acrolein and the specific residence time used (optimal for glycerol dehydration on Nb-V-HTB structures), which is too low to efficiently convert acrolein into acrylic acid on Mo-V-(W) laminar oxides [REF]. This conclusion was confirmed by reacting acrolein: good acrylic acid selectivity was obtained on Mo-V-(W) oxide, but with low conversion (figure $\mathrm{N}+10$ ).

As already reported for glycerol oxidehydration, the lack of acid sites in laminar Mo-V-(W) is also evident from the catalytic behavior shown in methanol oxidation (fig. $\mathrm{N}+9$ ); indeed the acid catalyzed route to DME was very low. On the other hand this system showed to be very selective in the oxidation of methanol to formaldehyde: a maximum aldehyde selectivity equal to $93 \%$ was registered at $87 \%$ methanol conversion $\left(\mathrm{T} 350^{\circ} \mathrm{C}\right)$. At low temperature, we also noticed the 
formation of dimethoxymethane, which may derive from the acetalization of formaldehyde with the unconverted methanol. On the other hand, because of the low specific surface area of this catalyst, in order to obtain methanol conversions close to those obtained by both $\mathrm{W}-\mathrm{V}$ and $\mathrm{W}-\mathrm{V}-\mathrm{Nb}$ catalysts, higher contact time (0.12 s) was needed as compared to that used with the latter systems (0.06 s). Josè: ARE THESE VALUES of contact time CORRECT ?

\section{Conclusions}

The studies carried out on both HTBs and laminar oxides have led to draw important conclusions on the features needed by multifunctional catalysts for the one-pot oxidehydration starting from oxygenated compounds. Indeed, the consecutive oxidation step must be fast compared to the dehydration one, in order to avoid the formation of heavy compounds generated by both ketals formation and oligomerisation reactions that take place from the intermediately formed aldehyde. Because of this, strongly oxidizing conditions, the latter being achieved by using oxygen partial pressures well above that needed for the stoichiometric oxidehydration of glycerol into acrylic acid, are necessary with the best performing $\mathrm{W}-\mathrm{V}-\mathrm{Nb}$ catalyst. The latter is characterized by higher surface area and higher concentration of stronger acid sites, properties which on one hand are important for an efficient dehydration of glycerol into acrolein, but on the other hand might favour the formation of undesired by-products. Under selected reaction conditions, an outstanding productivity to acrolein + acrylic acid close to $2 \mathrm{~h}^{-1}$ with an overall yield as high as $55 \%$ were achieved.

\section{Acknowledgements}

CIRI (Centro per la Ricerca Industriale), Università di Bologna, is acknowledged for the grant to A.C. The Valencia group also thanks the financial support of Dirección General de Investigación Científica y Técnica in Spain (Project CTQ2012-37925-C03-01). 


\section{References}

1. B. Katryniok, S. Paul, V. Belliere-Baca, P. Rey, F. Dumeignil, Green Chem., 2010, 12, 20792098.

2. P. Pin Oh, H. L. Nang Lau, J. Chen, M. Fong Chong, Y. May Choo, Renewable and Sustainable Energy Reviews, 2012, 16, 5131-5145.

3. E. Atabani, A.S. Silitonga, I. Anjum Badruddin, T.M.I. Mahlia, H.H. Masjuki, S. Mekhilef, Renewable and Sustainable Energy Reviews, 2012, 16, 2070-2093.

4. B. Katryniok, S. Paul,M. Capron, F. Dumeignil, ChemSusChem, 2009, 2, 719- 730.

5. J. A. Kenar, Lipid Technology, November 2007, Vol. 19, No. 11.

6. James M. Clomburg, Ramon Gonzalez, Trends in Biotechnology January 2013, Vol. 31, No. 1

7. M. Ayoub, A.Z. Abdullah, Renewable and Sustainable Energy Reviews 16 (2012) 2671- 2686

8. A. Martin, U. Armbruster, H. Atia, Eur. J. Lipid Sci. Technol. 114 (2012) 10-23.

9. H. Atia, U. Armbruster, A. Martin, J. Catal. 258 (2008) 71-82.

10. H. Atia, U. Armbruster, A. Martin, Appl. Catal. A 393 (2011) 331-339.

11. S. Erfle, U. Armbruster, U. Bentrup, A. Martin, A. Brückner, Appl. Catal. A 391 (2011) 102109.

12. B. Katryniok S. Paul, M. Capron, C. Lancelot, V. Bellière-Baca, P. Rey, F. Dumeignil, Green Chem. 12 (2010) 1922-1925.

13. S.-H. Chai, H.-P. Wang, Y. Liang, B.-Q. Xu, J. Catal. 250 (2007) 342-349.

14. S.-H. Chai, H.-P. Wang, Y. Liang, B.-Q. Xu, Green Chem. 10 (2008) 1087-1093.

15. S.-H. Chai, H.-P. Wang, Y. Liang, B.-Q. Xu, Appl. Catal. A 353 (2009) 213-222.

16. A. Ulgen, W.F. Hoelderich, Catal. Lett. 131 (2009) 122-128.

17. A. Ulgen, W.F. Hoelderich, Appl. Catal. A 400 (2011) 34-38. 
18. C.-J. Jia, Y. Liu, W. Schmidt, A.-H. Lu, F. Schüth, J. Catal. 269 (2010) 71-79.

19. A. Corma, G.W. Huber, L. Sauvanaud, P. O’Connor, J. Catal. 257 (2008) 163-171.

20. Y.T. Kim, K.-D. Jung, E. Duck Park, Microp. Mesop. Mater. 131 (2010) 28-36.

21. Y.T. Kim, K.-D. Jung, E. Duck Park, Appl. Catal. A 393 (2011) 275-287.

22. E. Tsukuda, S. Sato, R. Takahashi, T. Sodesawa, Catal. Commun. 8 (2007) 1349-1353.

23. Q. Liu, Z. Zhang, Y. Du, J. Li, X. Yang, Catal. Lett. 127 (2009) 419-428.

24. W. Suprun, M. Lutecki, T. Haber, H. Papp, J. Mol. Catal. A 309 (2009) 71-78.

25. W. Suprun, M. Lutecki, R. Gläser, H. Papp, J. Mol. Catal. A 342-343 (2011) 91-100.

26. B. Rafii Sereshki, S.-J. Balan, G. S. Patience, J.-L. Dubois, Ind. Eng. Chem. Res. 49 (2010) 1050-1056.

27. F. Cavani, S. Guidetti, L. Marinelli, M. Piccinini, E. Ghedini, M. Signoretto, Appl. Catal. B 100 (2010) 197-204.

28. F. Cavani, S. Guidetti, C. Trevisanut, E. Ghedini, M. Signoretto, Appl. Catal. A 409-410 (2011) 267-278.

29. P. Lauriol-Garbay J.M.M. Millet, S. Loridant, V. Bellière-Baca, P. Rey, J. Catal. 280 (2011) 6876.

30. P. Lauriol-Garbey, G. Postole, S. Loridant, A. Auroux, V. Belliere-Baca, P. Rey, J.M.M. Millet, Appl. Catal. B 106 (2011) 94- 102.

31. L. Ning, Y. Ding, W. Chen, L. Gong, R. Lin, Y. Li, Q. Xin, Chin. J. Catal. 29 (2008) 212-214.

32. J.L. Dubois, C. Duquenne and W. Hölderich, Eur. Patent 1874720 (2006), assigned to Arkema France.

33. J.L. Dubois, WO Patent, 2007/090991; WO Patent, 2008/007002, assigned to Arkema France.

34. F. Wang, J.-L. Dubois, W. Ueda, J. Catal. 268 (2009) 260-267. 
35. F. Wang, J. Deleplanque, J.-L. Dubois, J.-F. Devaux, W. Ueda, Catal. Today 157 (2010) 351358.

36. J. Xu, J.-L. Dubois, W. Ueda, ChemSusChem 3 (2010) 1383-1389.

37. F. Wang, J.-L. Dubois, W. Ueda, Appl. Catal. A 376 (2010) 25-32.

38. M. Dolores Soriano, P. Concepción, J. M. López Nieto, F. Cavani, S. Guidetti, C. Trevisanut, Green Chem. 13 (2011) 2954-2962.

39. N. Böhmer, T. Roussière, M. Kuba, S.A. Schunk, Combin. Chem. High Thr. Screen. 15 (2012) 123-135.

40. A. Witsuthammakul, T. Sooknoi, Appl. Catal. A 413-414 (2012) 109-116.

41. A. Chieregato, F. Basile, P. Concepción, S. Guidetti, G. Liosi, M. D. Soriano, C. Trevisanut, F. Cavani, J. M. López Nieto, Catalysis Today 197 (2012) 58- 65.

42. C. F. M. Pestana, A. C. O. Guerra, Glaucio B. F., C. C. Turci C. J. A. Mota, J. Braz. Chem. Soc., 2013, 24, No. 1, 100-105.

43. Josef Tichy, Applied Catalysis A: General , 157 (1997) 363-385.

44. Philip Kampe et al., Phys. Chem. Chem. Phys., 2007, 9, 3577-3589.

45. J.M. Tatibouët , Applied Catalysis A: General 148 (1997) 213-252

46. Mohit Badlani, Israel E. Wachs, Catalysis Letters Vol. 75, No. 3-4, 2001 


\begin{tabular}{|c|c|c|c|c|c|c|c|}
\hline $\begin{array}{c}\text { Sample } \\
\text { name }\end{array}$ & $\begin{array}{c}\text { Surface area } \\
\left(\mathrm{m}^{2} \mathrm{~g}^{-1}\right)\end{array}$ & \multicolumn{2}{|c|}{ TPD } & \multicolumn{2}{c|}{ TPR } & $\begin{array}{c}\text { Crystalline } \\
\text { phase }\end{array}$ & $\begin{array}{c}\text { Catalyst } \\
\text { composition }\end{array}$ \\
\hline WV & 19 & $\mu \mathrm{mol}_{\mathrm{NH} 3} \mathrm{~g}^{-1}$ & $\mu \mathrm{mol} \mathrm{NH}_{3} \mathrm{~m}^{-2}$ & Peak 1 & Peak 2 & & \\
\hline WVNb & 57,3 & 192 & 3.8 & 0.59 & 2.09 & $\mathrm{HTB}$ & $\mathrm{WV}_{0.14}$ \\
\hline MoVW & 5,8 & 20.5 & 3.4 & 0 & 3.99 & $\mathrm{HTB}$ & $\mathrm{WV}_{0.12} \mathrm{Nb}_{0.16}$ \\
\hline
\end{tabular}

- $\mathrm{H}_{2}$-TPR results: $\mathrm{H}_{2}$-uptake (in $\mathrm{mmol}_{\mathrm{H} 2} \mathrm{~g}^{-1}$ ) in the $450-550^{\circ} \mathrm{C}$ (peak 1) and 550-750 (peak 2) temperature region

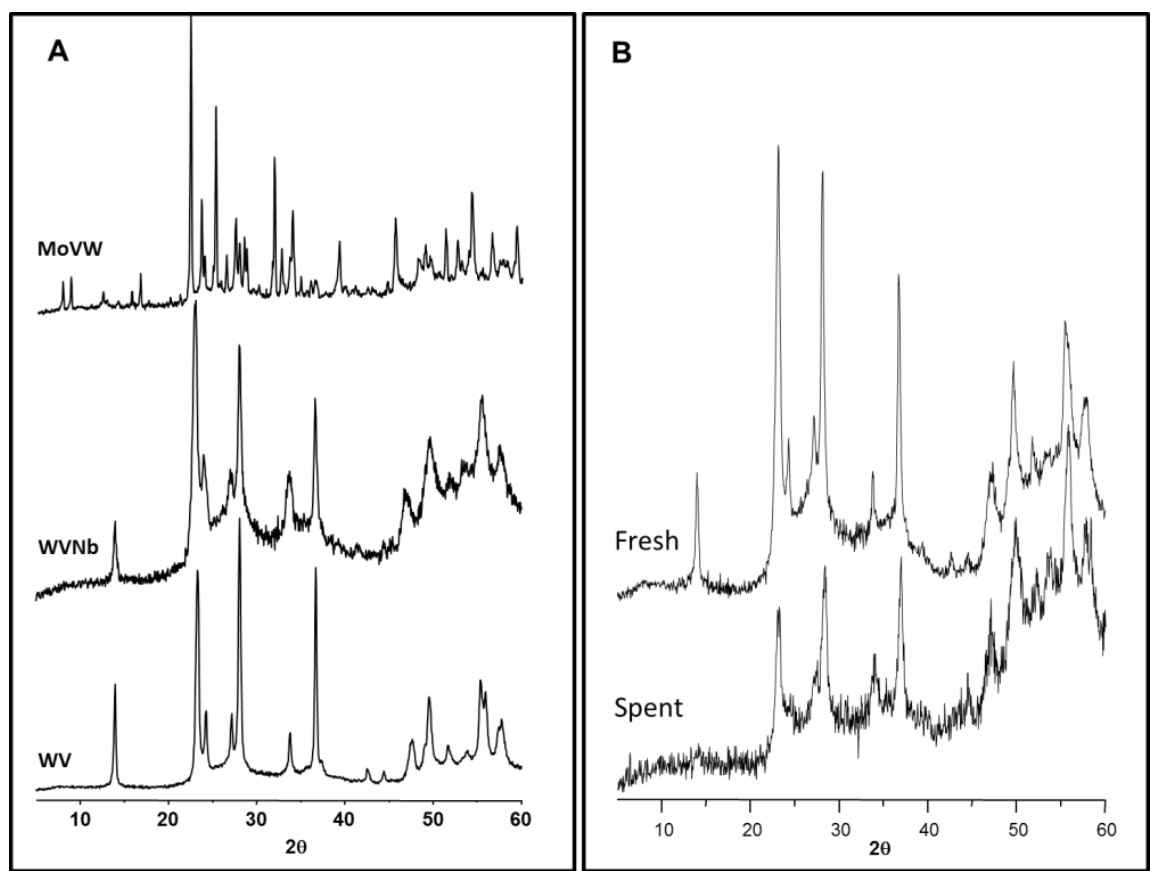

Fig. N. XRD spectra of the catalysts. A) Fresh samples; B) W-V-Nb sample, fresh and after 100 hours of time on stream test. 

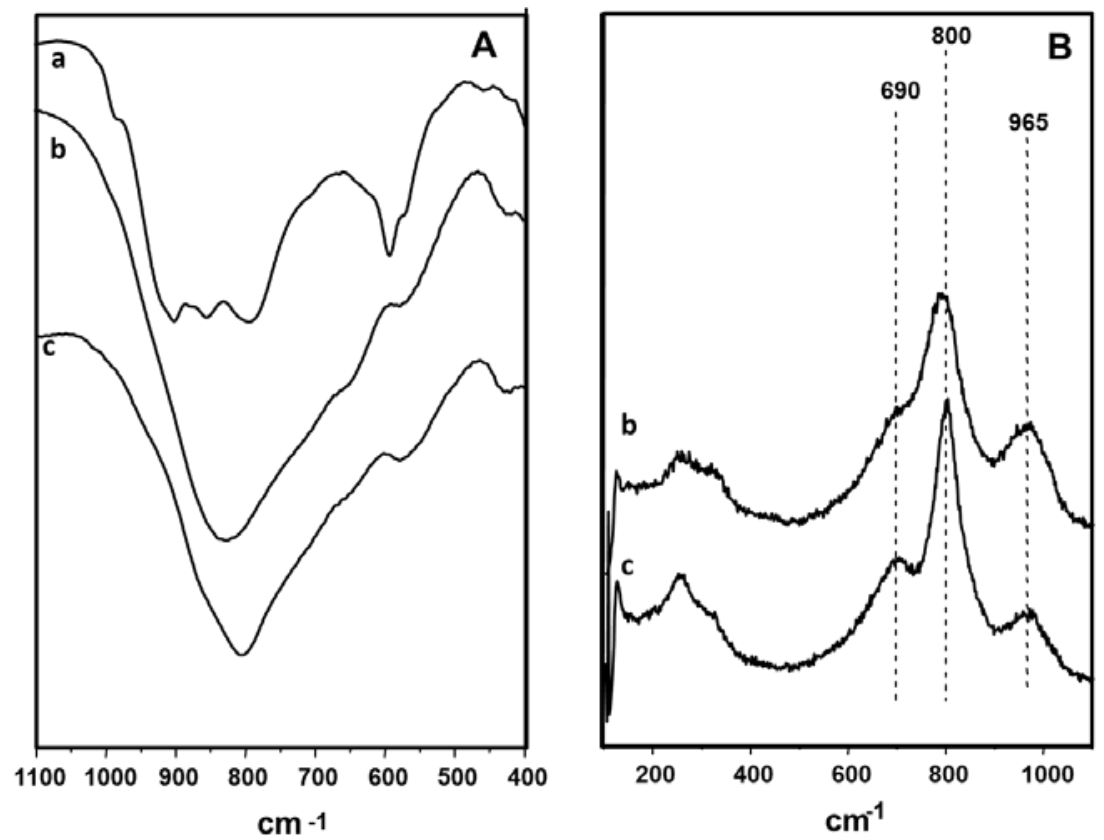

Fig. N. Spectra of fresh catalysts, Mo-V-W (a), W-V-Nb (b) and W-V (c).

A) FTIR spectra, B) Raman spectra

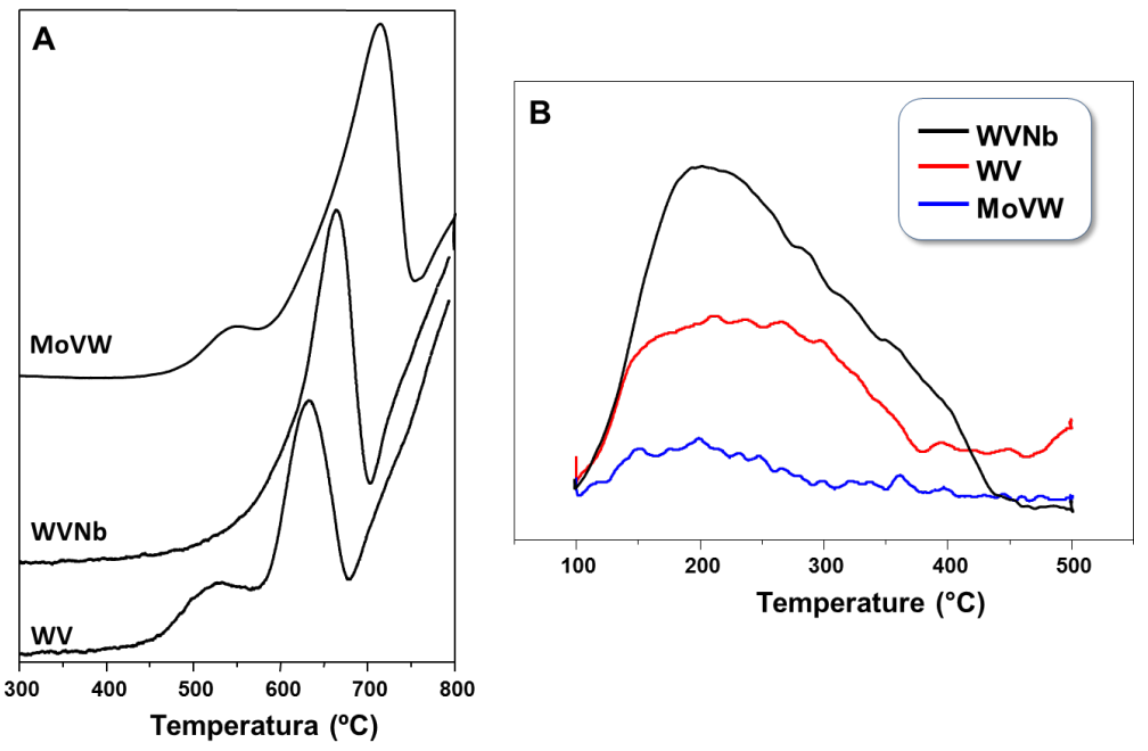

Fig. N. A) $\mathrm{H}_{2}-\mathrm{TPR} \quad$ B) $\mathrm{NH}_{3}-\mathrm{TPD}$ 
Figure $\mathrm{N}+1$

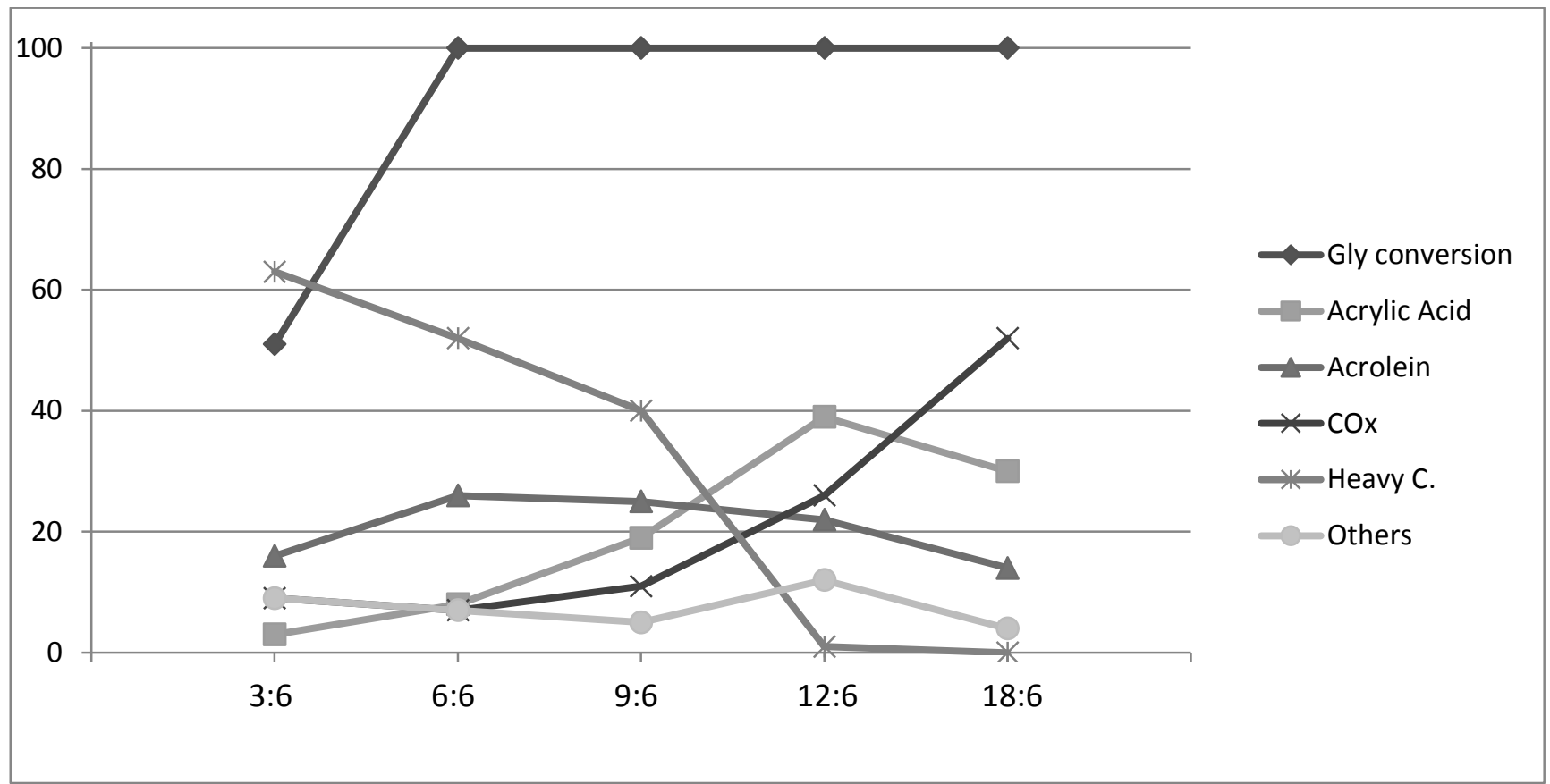

Fig. $\mathrm{N}+1$. W-V-Nb catalyst. Variable oxygen to glycerol ratio. Others: mainly acetaldehyde and acetic acid (in minor amounts, < 4\%: allylic alcohol, acetone, propionaldehyde, propionic acid and hydroxyacetone). 
Figure $\mathrm{N}+2$

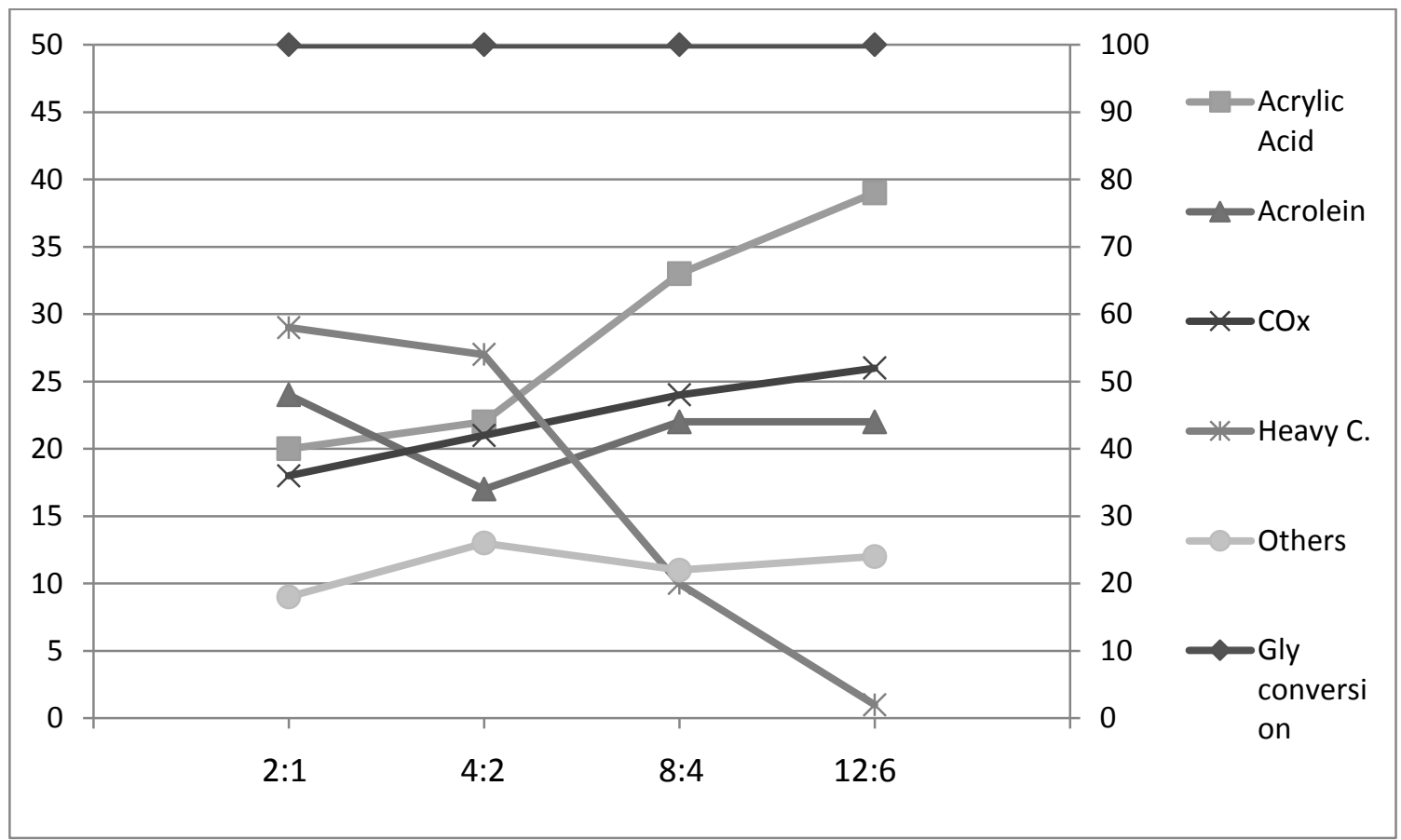

Fig. $\mathrm{N}+2 . \mathrm{W}-\mathrm{V}-\mathrm{Nb}$ catalyst. Constant Oxygen:Glycerol molar ratio (equal to 2). Others: mainly acetaldehyde and acetic acid (in minor amounts, < 4\%: allylic alcohol, acetone, propionaldehyde, propionic acid and hydroxyacetone). 
Figure $\mathrm{N}+4$
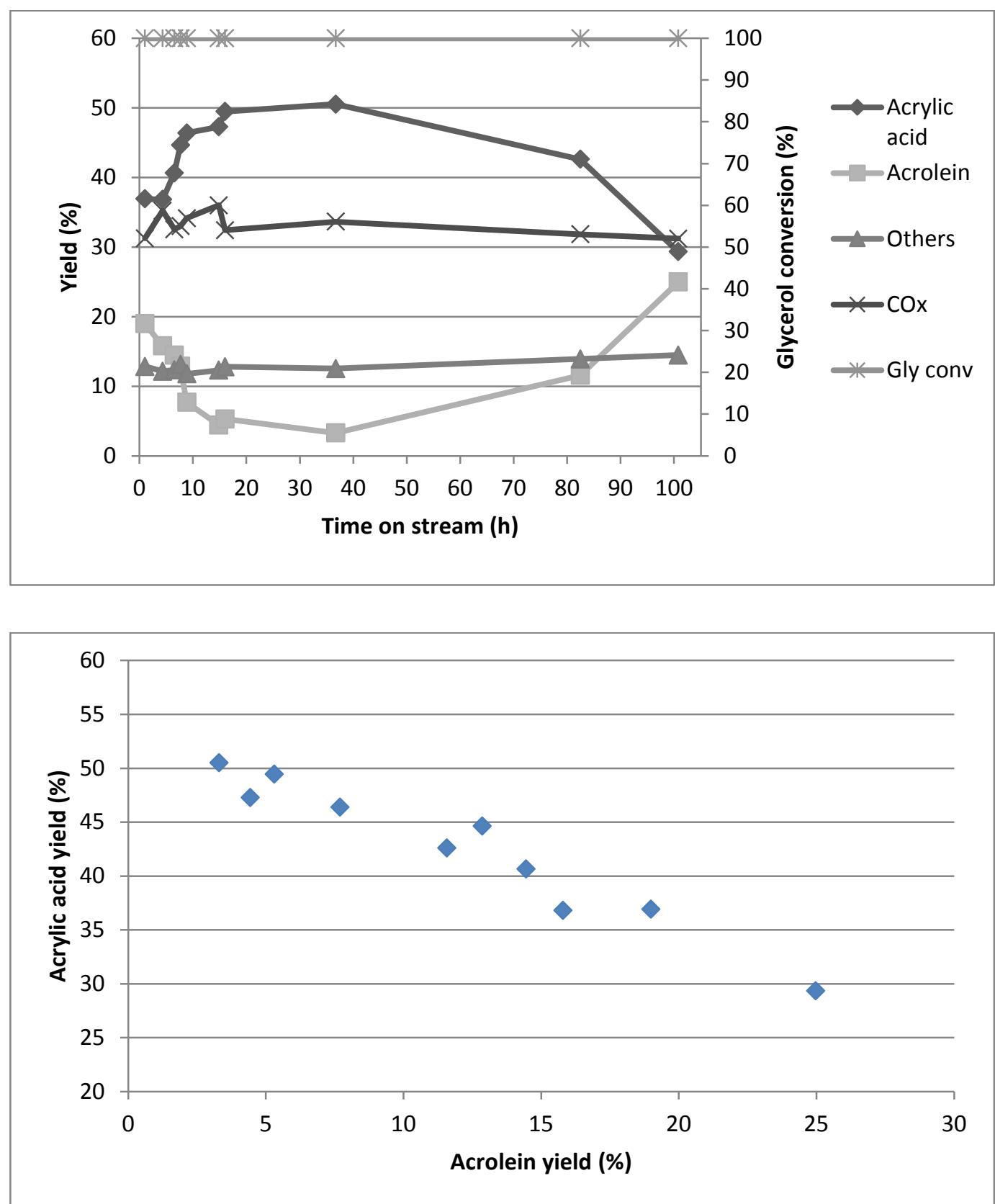

Fig. $\mathrm{N}+4$. Top: Time on stream test; feed condition Oxygen/Glycerol/ $\mathrm{H}_{2} \mathrm{O}=12 / 6 / 40$, tau $0.15 \mathrm{~s}$. 
Figure $\mathrm{N}+5$

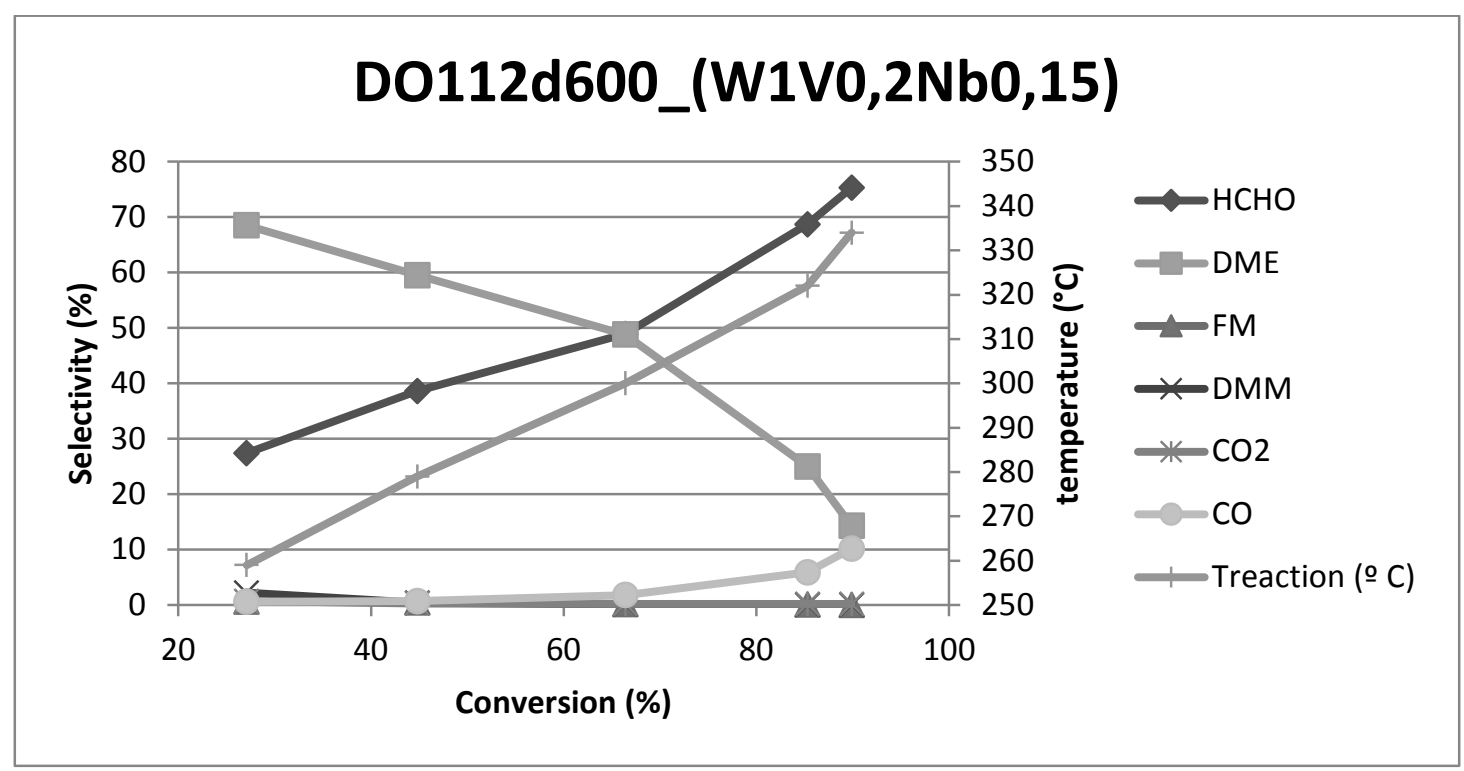

Fig. $\mathrm{N}+5$. Methanol oxidation on $\mathrm{W}$ 